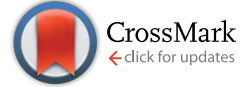

Cite this: J. Mater. Chem. A, 2015, 3, 24155

Received 27th July 2015

Accepted 25th October 2015

DOI: $10.1039 / \mathrm{c} 5$ ta05777a

www.rsc.org/MaterialsA

\section{Structural, optical and charge generation properties of chalcostibite and tetrahedrite copper antimony sulfide thin films prepared from metal xanthates $\uparrow$}

\begin{abstract}
Thomas Rath, Andrew J. MacLachlan, Michael D. Brown and Saif A. Haque*
Herein, we report on a solution based approach for the preparation of thin films of copper antimony sulfide, an emerging absorber material for third generation solar cells. In this work, copper and antimony xanthates are used as precursor materials for the formation of two different copper antimony sulfide phases: chalcostibite $\left(\mathrm{CuSbS}_{2}\right)$ and tetrahedrite $\left(\mathrm{Cu}_{12} \mathrm{Sb}_{4} \mathrm{~S}_{13}\right)$. Both phases were thoroughly investigated regarding their structural and optical properties. Moreover, thin films of chalcostibite and tetrahedrite were prepared on mesoporous $\mathrm{TiO}_{2}$ layers and photoinduced charge transfer in these metal sulfide/ $/ \mathrm{TiO}_{2}$ heterojunctions was studied via transient absorption spectroscopy. Photoinduced charge transfer was detected in both the chalcostibite as well as the tetrahedrite sample, which is an essential property in view of applying these materials as light-harvesting agents in semiconductor sensitized solar cells.
\end{abstract}

\section{Introduction}

Copper antimony sulfides are interesting absorber materials for sustainable, cost-efficient and scalable photovoltaics as they have high absorption coefficients, well suited band gaps and consist of abundant elements. However, while other metal chalcogenides like cadmium telluride, copper indium gallium sulfide (CIGS) or copper zinc tin sulfide (CZTS) are already well established as solar absorber materials, in contrast, copper antimony sulfide based materials have received limited attention to date. Copper antimony sulfide can be prepared in four different phases, which are $\mathrm{CuSbS}_{2}$ (chalcostibite), $\mathrm{Cu}_{12} \mathrm{Sb}_{4} \mathrm{~S}_{13}$ (tetrahedrite), $\mathrm{Cu}_{3} \mathrm{SbS}_{3}$ (skinnerite) and $\mathrm{Cu}_{3} \mathrm{SbS}_{4}$ (famatinite). ${ }^{1}$ These different copper antimony phases have high absorption coefficients over $10^{5} \mathrm{~cm}^{-1}$, p-type conductivity and band gaps in the range between 1.1 and $1.8 \mathrm{eV} \cdot{ }^{1-8}$ Among these four phases, the most promising band gap values with respect to highest theoretically achievable power conversion efficiencies (PCEs) are reported for $\mathrm{CuSbS}_{2}(1.4-1.5 \mathrm{eV})^{7,8}$ and $\mathrm{Cu}_{12} \mathrm{Sb}_{4} \mathrm{~S}_{13}$ (1.6$1.7 \mathrm{eV}) .^{1,2}$

To date, the main focus of research on copper antimony sulfide has been on materials synthesis. Several nanoparticle syntheses have been developed in the last years and the preparation of all four different phases of copper antimony sulfide

Department of Chemistry and Centre for Plastic Electronics, Imperial College London, Imperial College Road, London, SW7 2AZ, UK. E-mail: t.rath@imperial.ac.uk; s.a. haque@imperial.ac.uk

$\dagger$ Electronic supplementary information (ESI) available: Chemical structures of the used metal xanthates, additional XRD, SEM-EDX and UV-vis data. See DOI: $10.1039 / \mathrm{c} 5$ ta05777a has been reported. ${ }^{1-10}$ Methods like a hydrazine based route, ${ }^{7}$ sputtering, ${ }^{11}$ thermal evaporation, ${ }^{\mathbf{1 2}, 13}$ or sulfurization of electrodeposited metals ${ }^{\mathbf{1 4}, \mathbf{1 5}}$ have already been used for the formation of copper antimony sulfide thin films.

However, to date only a few studies dealt with the characterisation of copper antimony sulfides regarding photoelectrochemistry ${ }^{\mathbf{2 , 5}, \mathbf{8}}$ or application of these materials in solar cells. ${ }^{7,14,16,17}$ For $\mathrm{CuSbS}_{2}$ based thin film solar cells, a maximum PCE of $3.1 \%$ has been achieved so far. ${ }^{14}$ The same PCE was reported very recently for a metal sulfide sensitized solar cell with $\mathrm{CuSbS}_{2}$ as absorber material, which highlights the potential of $\mathrm{CuSbS}_{2}$ for this type of solar cells. ${ }^{17}$ As such, this presents a strong case for investigating copper antimony sulfides with focus on their application as absorbers in semiconductor sensitized solar cells.

In this work, we report a facile solution based route for the formation of copper antimony sulfide films using metal xanthates as precursors. In particular, we use this approach to fabricate copper antimony sulfide sensitized mesoporous metal oxide films. The presented route is fundamentally different to colloidal nanoparticle syntheses towards copper antimony sulfide, as in this approach, the copper antimony sulfide phases are formed in a solid state reaction directly on the substrate or in the mesoporous metal oxide scaffold without capping ligands. Metal xanthates are versatile metal-organic precursors for the formation of metal sulfides due to their solubility in various solvents ${ }^{18}$ and conversion to metal sulfides at relatively low temperatures $\left(140-200{ }^{\circ} \mathrm{C}\right)^{\mathbf{1 9}}$ and even at room temperature using UV-light treatment. ${ }^{20} \mathrm{~A}$ variety of metal sulfides have been synthesized employing this method including a range of binary 
metal sulfides, ${ }^{21-34}$ ternary $\left(\mathrm{CuInS}_{2}\right)^{35-37}$ and quaternary metal sulfides (CZTS). ${ }^{38}$ Moreover, this solution based route employing metal xanthates was initially used to prepare nanocomposites of metal sulfide nanoparticles in organic/polymeric matrices for the application in bulk heterojunction hybrid solar cells, ${ }^{21,39,40}$ but this method is also very well suited to prepare thin metal sulfide films on mesoporous metal oxide scaffolds for application in semiconductor sensitized solar cells. ${ }^{\mathbf{4 1 , 4 2}}$

In this paper, we report the synthesis of two copper antimony sulfide phases, chalcostibite and tetrahedrite. We show that by tuning the copper xanthate to antimony xanthate molar ratio two distinct phases of copper antimony sulfide can be realized - namely chalcostibite $\left(\mathrm{CuSbS}_{2}\right)$ and tetrahedrite $\left(\mathrm{Cu}_{12} \mathrm{Sb}_{4} \mathrm{~S}_{13}\right)$. Furthermore, we present a detailed structural and optical characterisation of these materials by X-ray diffraction, Raman spectroscopy, EDX measurements and UVvis spectroscopy. Moreover, we also report on transient absorption spectroscopic measurements of photoinduced charge transfer in copper antimony sulfide/mesoporous $\mathrm{TiO}_{2}$ films. Evidence of photoinduced charge transfer across the copper antimony sulfide/mesoporous $\mathrm{TiO}_{2}$ heterojunction demonstrates the potential of such architectures for solar cell applications.

\section{Experimental}

\subsection{Materials synthesis}

Synthesis of copper and antimony xanthates. Copper(I) $O$ 2,2-dimethylpentan-3-yl dithiocarbonate was synthesized according to literature. ${ }^{35}$ Synthesis of antimony(III) $O$-propan-2yl dithiocarbonate: potassium hydroxide was stirred in a $1: 1$ molar ratio with 2-propanol and a small amount of water. The solution was cooled in an ice bath followed by a dropwise addition of carbon disulfide to a slight excess (1.1 equiv.). The resulting slurry was stirred for $30 \mathrm{~min}$ before vacuum filtering and washing with diethyl ether. The potassium $O$-propan-2-yl dithiocarbonate was then recrystallized from methanol. To form the antimony xanthate, an aqueous solution of $\mathrm{SbCl}_{3}$ (acidified with $\mathrm{HCl}$ conc. to facilitate dissolution of $\mathrm{SbCl}_{3}$ ) was added to a rapidly stirring aqueous solution of the potassium xanthate in a molar ratio of $1: 3$ and stirred for $60 \mathrm{~min}$ at room temperature, whereby a precipitate is formed. The pale yellow product was filtered and washed with water followed by methanol. The product was then recrystallized from acetone.

${ }^{1} \mathrm{H}$ NMR (400 MHz, $\mathrm{CDCl}_{3}, \delta$ ): 5.64-5.55 (m, 3H, 3x CH), 1.44 (d, $18 \mathrm{H}, 6 \mathrm{x} \mathrm{CH}_{3}$ ) ppm. Elem. anal. calc. for $\mathrm{SbS}_{6} \mathrm{O}_{3} \mathrm{C}_{12} \mathrm{H}_{21}$ : C 27.33, H 4.01; found: C 27.38, H 4.09.

Preparation of copper antimony sulfide thin films. Precursor solutions were prepared by dissolving copper(I) O-2,2-dimethylpentan-3-yl dithiocarbonate and antimony(III) $O$-propan-2-yl dithiocarbonate separately in chlorobenzene (typical concen-

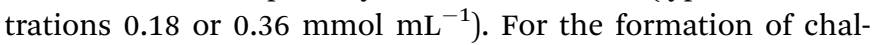
costibite the solutions were mixed in a $\mathrm{Cu}: \mathrm{Sb}$ molar ratio of $1: 1$ and for the formation of tetrahedrite a molar ratio of $3: 1$ was needed. Subsequently after blending the solutions, 1 vol\% of $n$-hexylamine (with regard to the amount of chlorobenzene) was added to obtain a stable solution. Thin films of copper antimony sulfide were formed either on bare glass substrates or glass substrates covered with mesoporous $\mathrm{TiO}_{2}$ or mesoporous $\mathrm{ZrO}_{2}$ layers. Therefore, the precursor solutions were spin casted or drop coated on the respective substrates and heated on a hot plate to $300{ }^{\circ} \mathrm{C}$ for $15 \min \left(200-350{ }^{\circ} \mathrm{C}\right.$ for the XRD study) in $\mathrm{N}_{2}$ atmosphere in a glove box, whereby the precursors were thermally converted into copper antimony sulfide. By the applied coating techniques, typical layer thicknesses of 50-100 nm (spin coating) and 1-2 $\mu \mathrm{m}$ (drop coating) were obtained.

Mesoporous $\mathrm{TiO}_{2}$ or $\mathrm{ZrO}_{2}$ layers were prepared by spin casting a $\mathrm{TiO}_{2}$ paste (30 NR-D, Dyesol) diluted with terpineol ( $1: 2.5 \mathrm{w}: \mathrm{w}$ ) or a $\mathrm{ZrO}_{2}$ paste (Zr-Nanoxide Z/SP, Solaronix) diluted with terpineol $(1: 2.5 \mathrm{w}: \mathrm{w})$ on glass substrates. After spin coating, the films were dried for $5 \mathrm{~min}$ at $80{ }^{\circ} \mathrm{C}$ on a hot plate before they were sintered at $450{ }^{\circ} \mathrm{C}$ for $1 \mathrm{~h}$ in a furnace in ambient atmosphere.

\subsection{Characterisation}

${ }^{1} \mathrm{H}$ NMR spectra were recorded on a $400 \mathrm{MHz}$ Bruker Avance spectrometer. Elemental analyses were carried out on a Universal CHNS Elemental Analyzer Vario El III. X-ray diffraction (XRD) patterns were measured on a PANalytical X'Pert Pro MRD diffractometer using Ni filtered $\mathrm{Cu} \mathrm{K}_{\alpha}$ radiation at $40 \mathrm{kV}$ and $40 \mathrm{~mA}$. Raman spectroscopy was performed on a LabRAM Infinity spectrometer (Horiba) using a $633 \mathrm{~nm} \mathrm{He-Ne}$ laser. Scanning electron microscopy-electron dispersive X-ray (SEM-EDX) measurements were carried out on a JEOL 6400 scanning electron microscope operated at $20 \mathrm{kV}$. Scanning electron microscopic images were acquired on a LEO 1525 Field Emission Scanning Electron Microscope operated at $5 \mathrm{kV}$ using an In Lens detector. Samples for SEM characterisations were coated with chromium $(5 \mathrm{~nm})$ by sputtering before the measurements.

Transmittance and reflectance spectra for the determination of the optical absorption coefficient as well as the absorption spectra were recorded on a Shimadzu 2600 spectrophotometer equipped with an ISR-2600Plus integrating sphere attachment. The optical band gaps were estimated from $(\alpha h v)^{2} v s . h v$ plots by extrapolating the linear part of the function. The copper antimony sulfide films used for the band gap determination had a thickness of $60 \mathrm{~nm}$. Layer thicknesses were measured using a Veeco Dektak surface profiler.

Microsecond transient absorption spectroscopy ( $\mu \mathrm{s}-\mathrm{TAS}$ ) measurements were performed by exciting the samples in inert atmosphere using a dye laser (Photon Technology International Inc. GL-301) pumped by a nitrogen laser (Photon Technology International Inc. GL-3300). A $100 \mathrm{~W}$ quartz halogen lamp (Bentham, IL 1) with a stabilized power supply (Bentham, 605) was used as a probe light source. A silicon photodiode (Hamamatsu Photonics, S1722-01) was used to detect the probe light passing through the sample and the signal was amplified before being passed through electronic band-pass filters (Costronics Electronics). The amplified signal was collected with a digital oscilloscope (Tektronics, DPO3012), which was synchronized with a trigger signal from the pump laser pulse from a photodiode (Thorlabs Inc., DET210). 


\section{Results and discussion}

Fig. 1 shows the X-ray diffraction patterns of the prepared copper antimony sulfide phases chalcostibite and tetrahedrite, the phases with the most promising properties for photovoltaic applications. The formation of these two materials could be realized by adjusting the molar ratios of the copper and antimony xanthates (the corresponding chemical structures are given in Fig. S1 in the ESI $\dagger$ ). For the preparation of copper antimony sulfide, a copper xanthate bearing a 2,2-dimethylpentyl alkyl side chain and an antimony xanthate carrying an isopropyl alkyl moiety, were chosen. By mixing these two compounds in a chlorobenzene solution, a stable precursor solution for spin casting the precursor films was obtained by adding 1 vol\% of $n$-hexylamine, which reacts with the metal xanthates to dialkylthiocarbamates. ${ }^{19}$ These particular compounds were chosen because (i) copper xanthates with shorter, non-branched side chains are not soluble in chlorobenzene, ${ }^{35}$ and (ii) using antimony xanthates with shorter linear side chains, e.g. antimony ethyl xanthate leads to precipitation of the copper xanthate in the chlorobenzene solution. Antimony 2,2-dimethylpentyl xanthate would result in a stable precursor solution in combination with copper 2,2-dimethylpentyl xanthate, however, the synthesis of this compound resulted in a liquid oily product and it was not possible to isolate it in crystalline form.

Using a $1: 1$ molar ratio of the selected copper 2,2-dimethylpentyl and antimony isopropyl xanthate leads to chalcostibite $\left(\mathrm{CuSbS}_{2}\right)$ while a $3: 1$ molar ratio results in the formation of the tetrahedrite $\left(\mathrm{Cu}_{12} \mathrm{Sb}_{4} \mathrm{~S}_{13}\right)$ phase. The formation of these copper antimony sulfides proceeds via a solid state reaction whereby the involved metal xanthates in the precursor layer decompose upon thermal treatment and are converted into the respective metal sulfides. The by-products of the thermal decomposition are volatile and leave the layer during the heating step. ${ }^{21,35}$

It is apparent that the X-ray patterns of the samples (molar ratios of $1: 1$ and $3: 1$ ) heated to $200{ }^{\circ} \mathrm{C}$ for $15 \mathrm{~min}$ appear quite similar. The peaks are rather broad, which indicates very small crystallite sizes (as estimated using Scherrer equation) and/or not fully developed crystal structures with partly amorphous character at this temperature. However, in the X-ray diffractograms of samples heated to $250{ }^{\circ} \mathrm{C}$, the characteristic peak patterns of the different copper antimony sulfide phases can be clearly identified (Fig. 1A and B). The sample in Fig. 1A, prepared using a molar ratio of copper and antimony xanthate of $1: 1$, exhibits an orthorhombic crystal structure matching well with the reference pattern for chalcostibite (PDF 00-0441417). The material prepared using a $3: 1$ molar ratio (Fig. 1B) shows a cubic crystal structure of tetrahedrite (PDF 01-0880282). Moreover, the peaks become much narrower indicating an increased primary crystallite size for the samples annealed at $250{ }^{\circ} \mathrm{C}$. Compared to an alternative solution based method for the fabrication of $\mathrm{CuSbS}_{2}$ using metal chlorides and thiourea as precursors, ${ }^{17}$ the metal xanthate based route reported herein has the advantage that crystalline phase-pure material (according to the XRD pattern) is obtained by heating the samples to $250{ }^{\circ} \mathrm{C}$, while for the metal salt based route an annealing step at $500{ }^{\circ} \mathrm{C}$ was necessary to avoid the secondary phase $\mathrm{Sb}_{2} \mathrm{~S}_{3}$.

It can be seen in Fig. 1A that upon increasing the annealing temperature from $250{ }^{\circ} \mathrm{C}$ to $300{ }^{\circ} \mathrm{C}$ and $350{ }^{\circ} \mathrm{C}$, the X-ray patterns of the chalcostibite samples show little or no change indicating no further evolution of the crystallite sizes. However, in the tetrahedrite sample, the full width at half maximum (FWHM) of the peaks becomes narrower with higher temperature treatment. Fig. $\mathrm{S} 2 \uparrow$ shows the primary crystallite sizes of the samples as a function of annealing temperature. According to an estimation using Scherrer equation (the FWHMs of the 501 and the 222 peaks of chalcostibite and tetrahedrite were used, respectively) the primary crystallite sizes are approx. $70 \mathrm{~nm}$ in the chalcostibite samples annealed at 250, 300 and $350{ }^{\circ} \mathrm{C}$, while the sizes increase from 15 to $45 \mathrm{~nm}$ in the tetrahedrite sample. This shows that the presented method affords control of the nanocrystal size of tetrahedrite by the applied temperature.

Fig. 2 shows the Raman spectra of both copper antimony sulfide phases prepared at $300{ }^{\circ} \mathrm{C}$. The chalcostibite sample
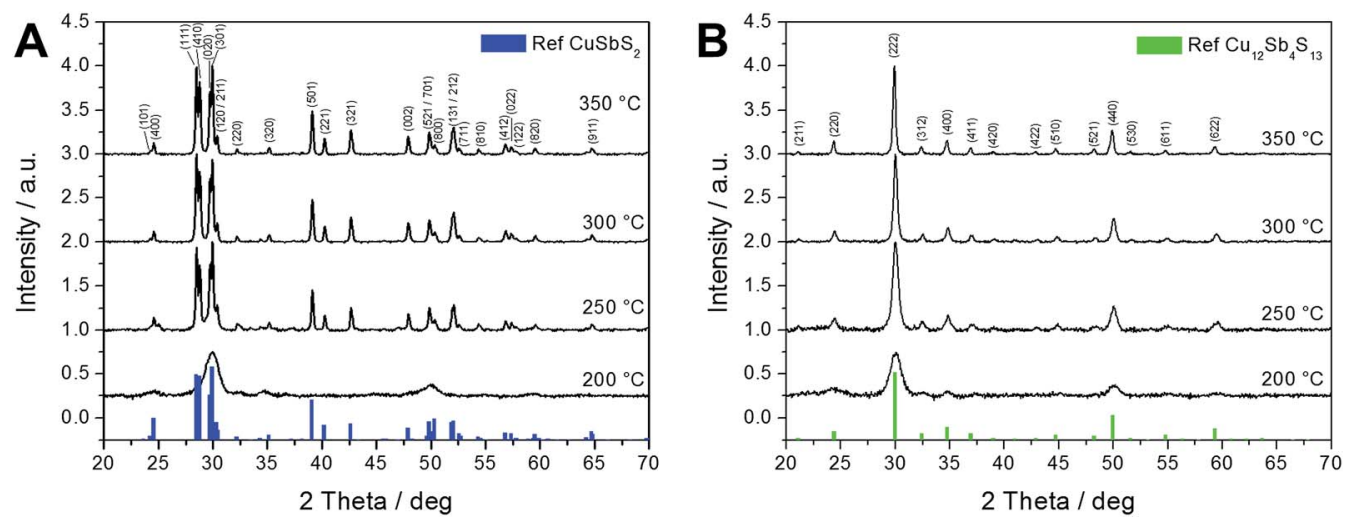

Fig. 1 X-ray diffraction patterns of chalcostibite (A) and tetrahedrite (B) layers annealed at different temperatures $\left(200-350{ }^{\circ} \mathrm{C}\right)$ along with the corresponding reference patterns (CuSbS 2 : PDF 00-044-1417; $\mathrm{Cu}_{12} \mathrm{Sb}_{4} \mathrm{~S}_{13}$ : PDF 01-088-0282). The main peaks in the patterns are labelled with their Miller indices. 

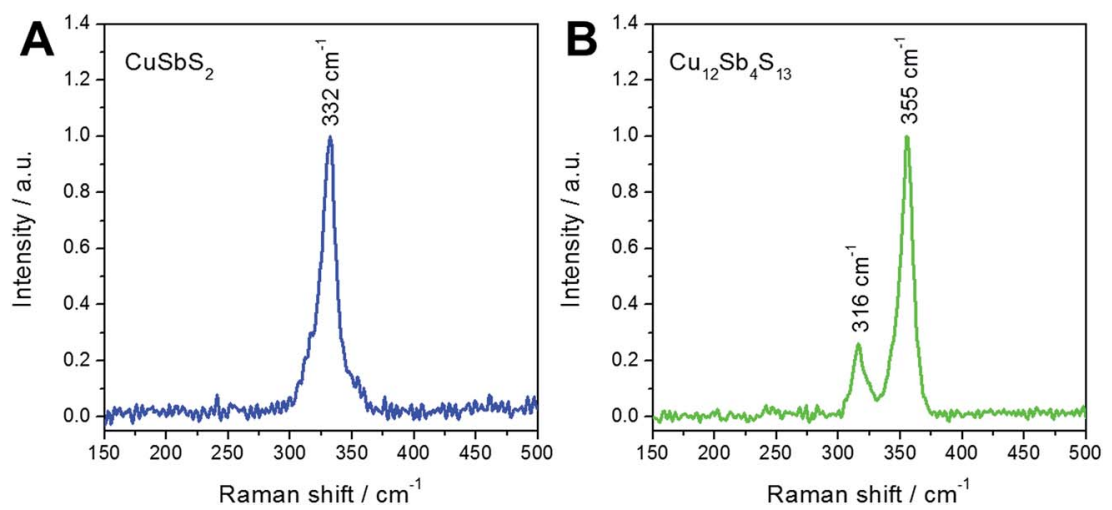

Fig. 2 Raman spectra of chalcostibite (A) and tetrahedrite (B) layers annealed at $300^{\circ} \mathrm{C}$.

exhibits a peak at $332 \mathrm{~cm}^{-1}$, while in the Raman spectrum of the tetrahedrite sample two peaks at $316 \mathrm{~cm}^{-1}$ and $355 \mathrm{~cm}^{-1}$ are observed. The Raman spectra presented in Fig. 2A and B are in agreement with reference data. ${ }^{43}$

Next, the chemical compositions of the thin films were analysed via SEM-EDX spectroscopy. The EDX spectra (Fig. S3, ESI $\dagger$ ) show the characteristic X-ray lines of the three elements copper, antimony and sulfur. In order to determine the relative amounts of copper, antimony and sulfur in the films, $\mathrm{Cu} \mathrm{K}, \mathrm{Sb} \mathrm{L}$ and S K series were used. In this way, the chemical compositions of both samples were determined and compared to the theoretical values (see Table 1). As expected, for both chalcostibite and tetrahedrite samples the $\mathrm{Cu}: \mathrm{Sb}: \mathrm{S}$ ratio matches well with theoretical values.

The absorption properties of the chalcostibite and tetrahedrite thin films deposited on glass are presented in Fig. 3 . The chalcostibite sample shows a broad absorption over a wide wavelength range with an onset at approx. $800 \mathrm{~nm}$. The band gap values were estimated using Tauc plots, which are shown as insets in Fig. 3A and B. This analysis leads to a band gap of $1.57 \mathrm{eV}$ for the chalcostibite sample. The soft absorption onset at higher wavelengths suggests also an indirect band gap of the material, which is approx. $1.1 \mathrm{eV}$ (see Fig. S4, ESI†). Similar values for direct and indirect band gap are also reported for chalcostibite nanoparticles prepared via colloidal synthesis routes. ${ }^{1,5,9,44,45}$ Compared to the chalcostibite sample, the absorption onset of the tetrahedrite sample is slightly blueshifted and a direct band gap of $1.74 \mathrm{eV}$ was determined as expected for this material according to previous reports on bulk tetrahedrite as well as nanoparticles., ${ }^{2,46}$ No indirect band gap could be determined for the tetrahedrite sample by linear fitting

Table 1 Chemical composition of $\mathrm{CuSbS}_{2}$ and $\mathrm{Cu}_{12} \mathrm{Sb}_{4} \mathrm{~S}_{13}$ determined by SEM-EDX measurements

\begin{tabular}{lllll}
\hline Material & & $\mathrm{Cu} / \mathrm{at} \%$ & $\mathrm{Sb} / \mathrm{at} \%$ & $\mathrm{~S} / \mathrm{at} \%$ \\
\hline $\mathrm{CuSbS}_{2}$ & Sample & $25.7 \pm 0.3$ & $25.3 \pm 0.2$ & $49.1 \pm 0.5$ \\
& Theoretical & 25.0 & 25.0 & 50.0 \\
$\mathrm{Cu}_{12} \mathrm{Sb}_{4} \mathrm{~S}_{13}$ & Sample & $39.3 \pm 0.4$ & $14.1 \pm 0.6$ & $46.5 \pm 0.4$ \\
& Theoretical & 41.4 & 13.8 & 44.8
\end{tabular}

of $(\alpha h \nu)^{1 / 2}$ as a function of the photon energy which is consistent with the literature. ${ }^{1}$ The absorption coefficients of both copper antimony sulfide samples are higher than $10^{5} \mathrm{~cm}^{-1}$ in the wavelength range under $600 \mathrm{~nm}$. These high absorption coefficients together with well-suited band gaps make both phases interesting for PV applications.

We now consider the interfacial charge transfer processes in copper antimony sulfide sensitized $\mathrm{TiO}_{2}$ architectures. For this purpose, laser based microsecond-millisecond transient absorption spectroscopy was employed. ${ }^{47-49}$ Thin films of chalcostibite and tetrahedrite were prepared on mesoporous $\mathrm{TiO}_{2}$ films as schematically illustrated in Fig. 4A. In a first step, the metal xanthate containing precursor solution was spin casted onto the mesoporous $\mathrm{TiO}_{2}$ films whereby the $\mathrm{TiO}_{2}$ nanoparticles are covered by the metal xanthates. Subsequent thermal treatment leads to the formation of metal sulfide sensitized $\mathrm{TiO}_{2}$ films. SEM images of a bare mesoporous $\mathrm{TiO}_{2}$ layer as well as mesoporous $\mathrm{TiO}_{2}$ layers sensitized with chalcostibite and tetrahedrite (thicknesses of $\mathrm{TiO}_{2}$ films: approx. $1 \mu \mathrm{m}$ ) are shown in Fig. 4B-D. Comparing the SEM image in Fig. $4 \mathrm{~B}$ with the images in Fig. $4 \mathrm{C}$ and $\mathrm{D}$, it can be seen upon careful inspection that the $\mathrm{TiO}_{2}$ nanoparticles are covered with a thin film of the metal sulfide. Moreover, it was confirmed by X-ray diffraction measurements that chalcostibite and tetrahedrite are also formed on the mesoporous $\mathrm{TiO}_{2}$ layer in the same way as on the glass substrates. The X-ray diffraction patterns of chalcostibite and tetrahedrite prepared on mesoporous $\mathrm{TiO}_{2}$ are shown in Fig. S5 in the ESI $\dagger$ and the diffraction peaks are in line with the ones observed for the copper antimony sulfides prepared on glass (Fig. 1), barring the presence of two additional peaks stemming from $\mathrm{TiO}_{2}$ at 25.4 and $38.1^{\circ} 2$ theta. Absorption spectra of the chalcostibite and tetrahedrite films prepared on mesoporous $\mathrm{TiO}_{2}$ are depicted in Fig. S6. $\dagger$

Fig. 5 shows the results of the transient absorption spectroscopic investigations. Fig. $5 \mathrm{~A}$ and $\mathrm{B}$ show the transient absorption spectra of $\mathrm{TiO}_{2} /$ chalcostibite, $\mathrm{TiO}_{2} /$ tetrahedrite, $\mathrm{ZrO}_{2} /$ chalcostibite and $\mathrm{ZrO}_{2} /$ tetrahedrite samples measured $1 \mu \mathrm{s}$ after pulsed laser excitation (wavelength: $450 \mathrm{~nm}$ and laser fluency: $15 \mu \mathrm{J} \mathrm{cm}^{-2}$ ). The transient absorption spectra of the $\mathrm{TiO}_{2} /$ copper antimony sulfide heterojunctions show a broad absorption feature between 900 and $1600 \mathrm{~nm}$. This broad 

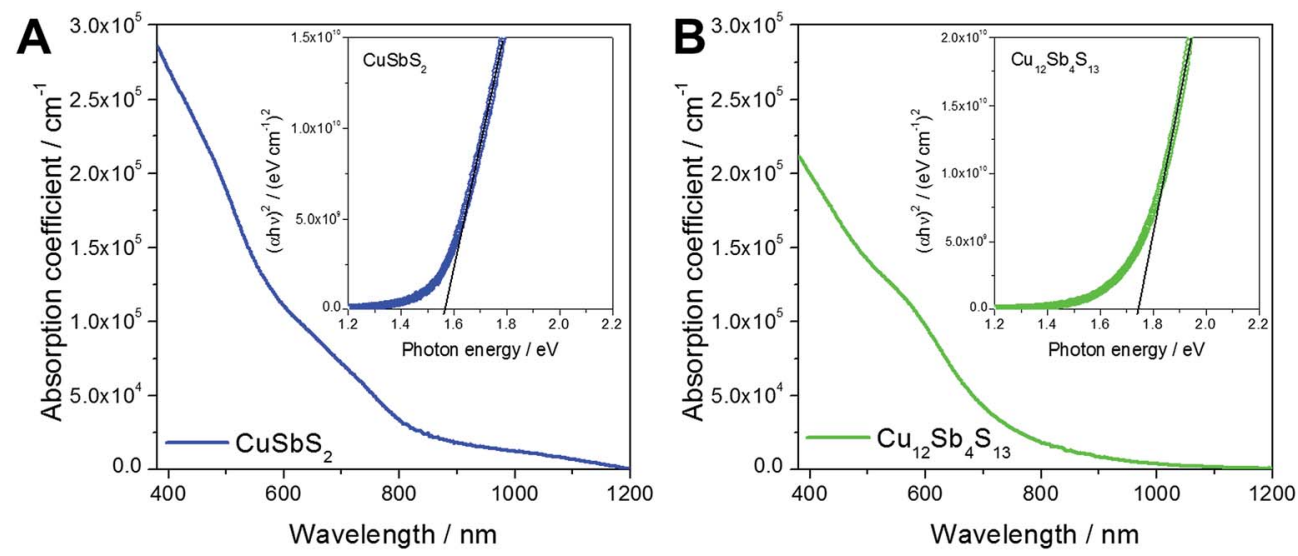

Fig. 3 Absorption coefficients of chalcostibite (A) and tetrahedrite (B) thin films annealed at $300{ }^{\circ} \mathrm{C}$ and the corresponding Tauc plots for band gap determination shown as insets.

absorption feature in this wavelength range is typical for electrons in $\mathrm{TiO}_{2}$ or holes in metal sulfides and the observed transient absorption spectrum is comparable to the spectra reported for mesoporous $\mathrm{TiO}_{2}$ sensitized with the binary metal chalcogenides CdS, $\mathrm{Sb}_{2} \mathrm{~S}_{3}$ or $\mathrm{Sb}_{2} \mathrm{Se}_{3}{ }^{41,50,51}$ The $\Delta \mathrm{OD}$ values of the $\mathrm{ZrO}_{2} /$ copper antimony sulfide reference samples are negligible over the whole wavelength range further indicating charge photogeneration in the $\mathrm{TiO}_{2}$ based assemblies. The lack of any transient absorption signal in the $\mathrm{ZrO}_{2}$ based films is consistent with the higher conduction band energy of $\mathrm{ZrO}_{2}$ (relative to $\left.\mathrm{TiO}_{2}\right)^{52}$ prohibiting electron injection from copper antimony sulfide to $\mathrm{ZrO}_{2}$.
Fig. 5C and $\mathrm{D}$ show the charge recombination kinetics $(\Delta \mathrm{OD}$, difference in optical density, versus time profile) in chalcostibite and tetrahedrite sensitized mesoporous $\mathrm{TiO}_{2}$ and $\mathrm{ZrO}_{2}$ films. These data were obtained by monitoring the transient absorption signal at $1400 \mathrm{~nm}$ following pulsed laser excitation of the samples (wavelength: $450 \mathrm{~nm}$ and laser fluency: $15 \mu \mathrm{J} \mathrm{cm}^{-2}$ ). As expected, a distinct signal is visible in the samples prepared on mesoporous $\mathrm{TiO}_{2}$ indicating the photoinduced generation of long-lived charges across the inorganic absorber/TiO ${ }_{2}$ heterojunction. Our observation of long-lived charge separation (lifetime in range of $1 \mathrm{~ms}-10 \mathrm{~ms}$ ) in the $\mathrm{TiO}_{2}$ based assemblies is in agreement with previous reports of charge recombination in $\mathrm{TiO}_{2} /$ metal sulfide films. ${ }^{41,50}$
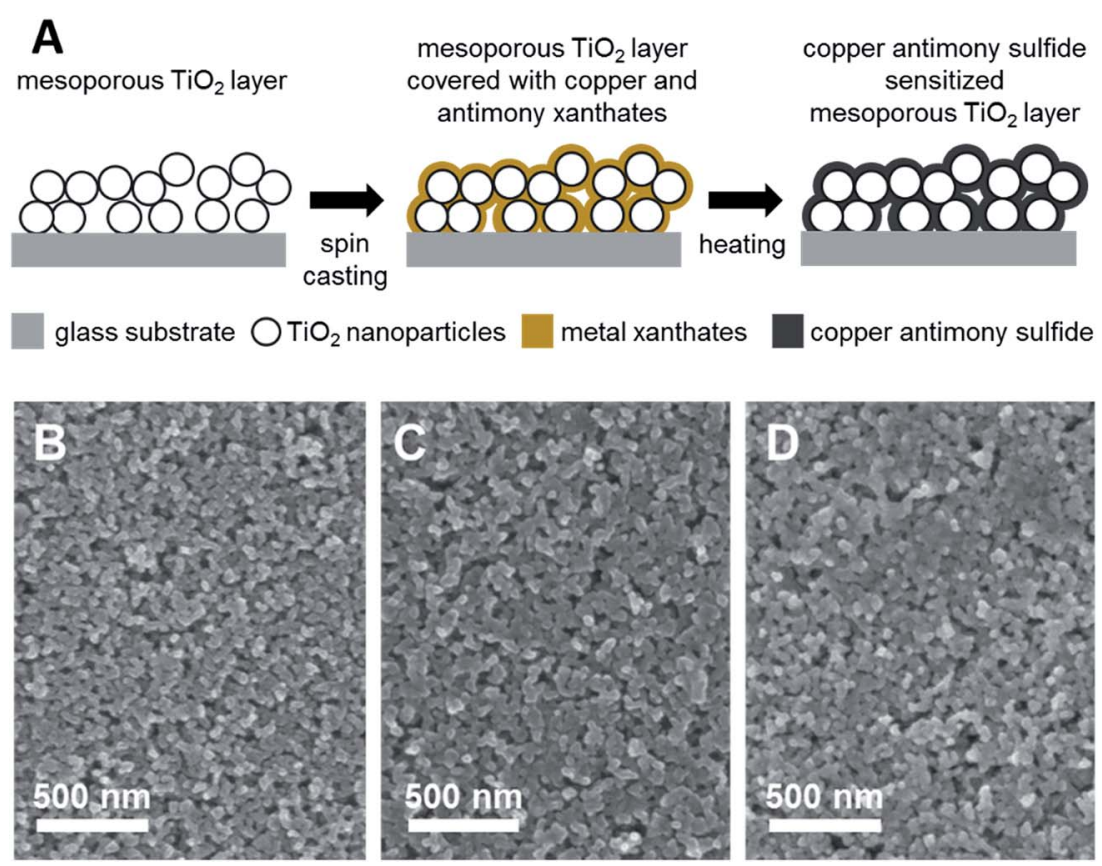

Fig. 4 Scheme illustrating the formation of a thin metal sulfide film on a mesoporous metal oxide scaffold using metal xanthates as precursors (A); SEM images of a mesoporous $\mathrm{TiO}_{2}$ film (B), covered with a thin film of chalcostibite (C) and tetrahedrite (D). The copper antimony sulfide films were annealed at $300^{\circ} \mathrm{C}$. 

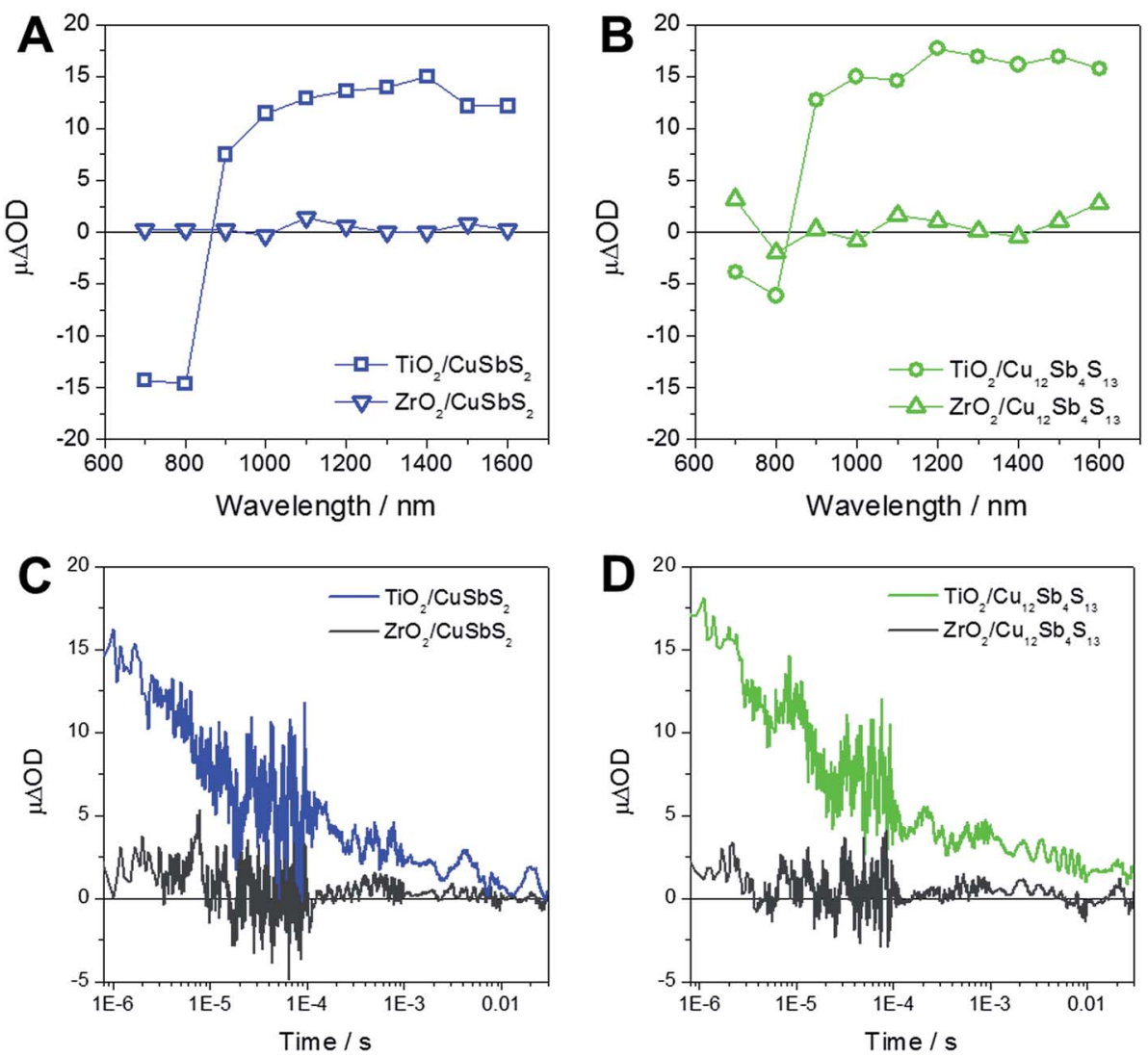

Fig. 5 Transient absorption spectra of mesoporous $\mathrm{TiO}_{2}$ and $\mathrm{ZrO}_{2}$ layers sensitized with $\mathrm{CuSbS}_{2}(\mathrm{~A})$ and $\mathrm{Cu}_{12} \mathrm{Sb}_{4} \mathrm{~S}_{13}(\mathrm{~B})$ measured $1 \mu \mathrm{s}$ after pulsed laser excitation (wavelength: $450 \mathrm{~nm}$ ) and the corresponding transient absorption kinetics ( $C$ and D) measured using a probe wavelength of $1400 \mathrm{~nm}$

Moreover, the long-lived charge separation in both $\mathrm{TiO}_{2} /$ chalcostibite and $\mathrm{TiO}_{2} /$ tetrahedrite films suggest that chalcostibite and tetrahedrite are well suited as light absorbers in semiconductor sensitized solar cells. As such, the use of these materials is particularly advantageous compared to the wellstudied current state of the art metal sulfide based material $\mathrm{Sb}_{2} \mathrm{~S}_{3},{ }^{53,54}$ as chalcostibite and tetrahedrite offer the prospect of superior light harvesting due to their smaller band gaps. ${ }^{17}$

\section{Conclusion}

Two phases of copper antimony sulfide, chalcostibite $\left(\mathrm{CuSbS}_{2}\right)$ and tetrahedrite $\left(\mathrm{Cu}_{12} \mathrm{Sb}_{4} \mathrm{~S}_{13}\right)$, were successfully prepared as thin films on glass and on mesoporous metal oxide layers via a solution based precursor route. Copper and antimony xanthates were dissolved in chlorobenzene and after spin casting the solution on the respective substrates, the metal xanthates are converted into copper antimony sulfide upon thermal treatment. Employing a molar ratio of copper and antimony xanthate of $1: 1$ and $3: 1$ in the precursor solution led to the formation of chalcostibite and tetrahedrite phases, respectively, which was confirmed by X-ray diffraction, Raman spectroscopy and SEM-EDX measurements. The characterisation of the optical properties revealed high absorption coefficients for both phases and bandgaps of 1.57 and $1.74 \mathrm{eV}$ are determined for the chalcostibite and tetrahedrite films, respectively. Based on their optical properties, both phases are well suited for photovoltaic applications, which was the reason for further investigation of the prepared materials focusing on charge photogeneration. Mesoporous $\mathrm{TiO}_{2}$ films sensitized with chalcostibite and tetrahedrite were studied using microsecond transient absorption spectroscopy and photoinduced charge transfer could be detected in both heterojunctions.

\section{Acknowledgements}

S. A. $\mathrm{H}$ acknowledges financial support from the Engineering and Physical Sciences Research Council (EPSRC) through (EP/ $\mathrm{H} 040218 / 2)$ and (EP/K010298/1) projects and from the European Community's Seventh Framework Programme (Nanomatcell, grant agreement number 308997). Financial support from the Austrian Science Fund (FWF) is acknowledged by TR (grant number: J3515-N20).

\section{References}

1 K. Ramasamy, H. Sims, W. H. Butler and A. Gupta, Chem. Mater., 2014, 26, 2891-2899.

2 J. van Embden, K. Latham, N. W. Duffy and Y. Tachibana, J. Am. Chem. Soc., 2013, 135, 11562-11571. 
3 D. Xu, S. Shen, Y. Zhang, H. Gu and Q. Wang, Inorg. Chem., 2013, 52, 12958-12962.

4 X. Qiu, S. Ji, C. Chen, G. Liu and C. Ye, CrystEngComm, 2013, 15, 10431-10434.

5 S. Ikeda, S. Sogawa, Y. Tokai, W. Septina, T. Harada and M. Matsumura, RSC Adv., 2014, 4, 40969-40972.

6 J. van Embden and Y. Tachibana, J. Mater. Chem., 2012, 22, 11466-11469.

7 B. Yang, L. Wang, J. Han, Y. Zhou, H. Song, S. Chen, J. Zhong, L. Lv, D. Niu and J. Tang, Chem. Mater., 2014, 26, 3135-3143.

8 C. Yan, Z. Su, E. Gu, T. Cao, J. Yang, J. Liu, F. Liu, Y. Lai, J. Li and Y. Liu, RSC Adv., 2012, 2, 10481-10484.

9 Y. Zou and J. Jiang, Mater. Lett., 2014, 123, 66-69.

10 K. Ramasamy, B. Tien, P. S. Archana and A. Gupta, Mater. Lett., 2014, 124, 227-230.

11 A. W. Welch, P. P. Zawadzki, S. Lany, C. A. Wolden and A. Zakutayev, Sol. Energy Mater. Sol. Cells, 2015, 132, 499506.

12 A. Rabhi, M. Kanzari and B. Rezig, Thin Solid Films, 2009, 517, 2477-2480.

13 D. Colombara, L. M. Peter, K. D. Rogers, J. D. Painter and S. Roncallo, Thin Solid Films, 2011, 519, 7438-7443.

14 W. Septina, S. Ikeda, Y. Iga, T. Harada and M. Matsumura, Thin Solid Films, 2014, 550, 700-704.

15 D. Colombara, L. M. Peter, K. D. Rogers and K. Hutchings, J. Solid State Chem., 2012, 186, 36-46.

16 R. E. Ornelas-Acosta, S. Shaji, D. Avellaneda, G. A. Castillo, T. K. Das Roy and B. Krishnan, Mater. Res. Bull., 2015, 61, 215-225.

17 Y. C. Choi, E. J. Yeom, T. K. Ahn and S. I. Seok, Angew. Chem., Int. Ed., 2015, 54, 4005-4009.

18 L. K. Macreadie, H. E. Maynard-Casely, S. R. Batten, D. R. Turner and A. S. R. Chesman, ChemPlusChem, 2015, 80, 107-118.

19 C. Fradler, T. Rath, S. Dunst, I. Letofsky-Papst, R. Saf, B. Kunert, F. Hofer, R. Resel and G. Trimmel, Sol. Energy Mater. Sol. Cells, 2014, 124, 117-125.

20 T. Rath, C. Padeste, M. Vockenhuber, C. Fradler, M. Edler, A. Reichmann, I. Letofsky-Papst, F. Hofer, Y. Ekinci and T. Griesser, J. Mater. Chem. A, 2013, 1, 11135-11140.

21 H. C. Leventis, S. P. King, A. Sudlow, M. S. Hill, K. C. Molloy and S. A. Haque, Nano Lett., 2010, 10, 1253-1258.

22 A. J. MacLachlan, T. Rath, U. B. Cappel, S. A. Dowland, H. Amenitsch, A.-C. Knall, C. Buchmaier, G. Trimmel, J. Nelson and S. A. Haque, Adv. Funct. Mater., 2015, 25, 409-420.

23 N. Bansal, L. X. Reynolds, A. MacLachlan, T. Lutz, R. S. Ashraf, W. Zhang, C. B. Nielsen, I. McCulloch, D. G. Rebois, T. Kirchartz, M. S. Hill, K. C. Molloy, J. Nelson and S. A. Haque, Sci. Rep., 2013, 3, 1531.

24 D. Barreca, E. Tondello, D. Lydon, T. R. Spalding and M. Fabrizio, Chem. Vap. Deposition, 2003, 9, 93-98.

25 F. Todescato, A. S. R. Chesman, A. Martucci, R. Signorini and J. J. Jasieniak, Chem. Mater., 2012, 24, 2117-2126.

26 N. Bansal, F. T. F. O'Mahony, T. Lutz and S. A. Haque, Adv. Energy Mater., 2013, 3, 986-990.
27 V. Kaltenhauser, T. Rath, W. Haas, A. Torvisco, S. K. Müller, B. Friedel, B. Kunert, R. Saf, F. Hofer and G. Trimmel, J. Mater. Chem. C, 2013, 1, 7825-7832.

28 A. J. MacLachlan, F. T. F. O'Mahony, A. L. Sudlow, M. S. Hill, K. C. Molloy, J. Nelson and S. A. Haque, ChemPhysChem, 2014, 15, 1019-1023.

29 J. M. Clark, G. Kociok-Köhn, N. J. Harnett, M. S. Hill, R. Hill, K. C. Molloy, H. Saponia, D. Stanton and A. Sudlow, Dalton Trans., 2011, 40, 6893-6900.

30 E. A. Lewis, P. D. McNaughter, Z. Yin, Y. Chen, J. R. Brent, S. A. Saah, J. Raftery, J. A. M. Awudza, M. A. Malik, P. O'Brien and S. J. Haigh, Chem. Mater., 2015, 27, 21272136.

31 D. P. Dutta, G. Sharma, S. Ghoshal, N. P. Kushwah and V. K. Jain, J. Nanosci. Nanotechnol., 2006, 6, 235-240.

32 S. Ghoshal, N. P. Kushwah, D. P. Dutta and V. K. Jain, Appl. Organomet. Chem., 2005, 19, 1257-1262.

33 N. Alam, M. S. Hill, G. Kociok-Köhn, M. Zeller, M. Mazhar and K. C. Molloy, Chem. Mater., 2008, 20, 6157-6162.

34 N. Pradhan, B. Katz and S. Efrima, J. Phys. Chem. B, 2003, 107, 13843-13854.

35 T. Rath, M. Edler, W. Haas, A. Fischereder, S. Moscher, A. Schenk, R. Trattnig, M. Sezen, G. Mauthner, A. Pein, D. Meischler, K. Bartl, R. Saf, N. Bansal, S. A. Haque, F. Hofer, E. J. W. List and G. Trimmel, Adv. Energy Mater., 2011, 1, 1046-1050.

36 M. Arar, M. Gruber, M. Edler, W. Haas, F. Hofer, N. Bansal, L. X. Reynolds, S. A. Haque, K. Zojer, G. Trimmel and T. Rath, Nanotechnology, 2013, 24, 484005.

37 A. Kharkwal, S. N. Sharma, K. Jain, L. Arora, P. Chawla, A. K. Singh and S. Chand, Colloid Polym. Sci., 2013, 291, 2607-2617.

38 A. Fischereder, A. Schenk, T. Rath, W. Haas, S. Delbos, C. Gougaud, N. Naghavi, A. Pateter, R. Saf, D. Schenk, M. Edler, K. Bohnemann, A. Reichmann, B. Chernev, F. Hofer and G. Trimmel, Monatsh. Chem., 2013, 144, 273283.

39 T. Rath and G. Trimmel, Hybrid Mater., 2014, 1, 15-36.

40 T. Rath, V. Kaltenhauser, W. Haas, A. Reichmann, F. Hofer and G. Trimmel, Sol. Energy Mater. Sol. Cells, 2013, 114, 38-42.

41 T. Lutz, A. MacLachlan, A. Sudlow, J. Nelson, M. S. Hill, K. C. Molloy and S. A. Haque, Phys. Chem. Chem. Phys., 2012, 14, 16192-16196.

42 F. T. F. O'Mahony, U. B. Cappel, N. Tokmoldin, T. Lutz, R. Lindblad, H. Rensmo and S. A. Haque, Angew. Chem., Int. Ed., 2013, 52, 12047-12051.

43 http://rruff.info/chalcostibite and http://rruff.info/ Tetrahedrite, accessed on June 22, 2015.

44 S. Suehiro, K. Horita, M. Yuasa, T. Tanaka, K. Fujita, Y. Ishiwata, K. Shimanoe and T. Kida, Inorg. Chem., 2015, 54, 7840-7845.

45 K. Ramasamy, H. Sims, W. H. Butler and A. Gupta, J. Am. Chem. Soc., 2014, 136, 1587-1598.

46 R. Jeanloz and M. L. Johnson, Phys. Chem. Minerals, 1984, 11, 52-54. 
47 S. A. Haque, T. Park, A. B. Holmes and J. R. Durrant, ChemPhysChem, 2003, 4, 89-93.

48 U. B. Cappel, S. A. Dowland, L. X. Reynolds, S. Dimitrov and S. A. Haque, J. Phys. Chem. Lett., 2013, 4, 4253-4257.

49 L. X. Reynolds, T. Lutz, S. Dowland, A. J. MacLachlan, S. King and S. A. Haque, Nanoscale, 2012, 4, 1561-1564.

50 F. T. F. O'Mahony, T. Lutz, N. Guijarro, R. Gómez and S. A. Haque, Energy Environ. Sci., 2012, 5, 9760-9764.
51 N. Guijarro, T. Lutz, T. Lana-Villarreal, F. O'Mahony, R. Gómez and S. A. Haque, J. Phys. Chem. Lett., 2012, 3, 1351-1356.

52 L. Chai, R. T. White, M. T. Greiner and Z. H. Lu, Phys. Rev. B: Condens. Matter Mater. Phys., 2014, 89, 035202.

53 Y. C. Choi, D. U. Lee, J. H. Noh, E. K. Kim and S. I. Seok, Adv. Funct. Mater., 2014, 24, 3587-3592.

54 T. Fukumoto, T. Moehl, Y. Niwa, M. K. Nazeeruddin, M. Grätzel and L. Etgar, Adv. Energy Mater., 2013, 3, 29-33. 